\title{
Exchange Rates and Export Growth in Asian Economies
}

\author{
Saadiah Mohamad \\ Faculty of Business Management \\ Universiti Teknologi MARA, Shah Alam, Selangor, Malaysia \\ E-mail: saadiah228@uitm.edu.my
}

Hj. Kamaruzaman Jusoff (Corresponding author)

Yale University

CEO-Environmental Science Centre, 21 Sachem St

New Haven, CT 06511, USA

E-mail: jusoff.kamaruzaman@yale.edu

\begin{abstract}
This paper discusses the impact of exchange rates on the export performance of selected Southeast Asian economies, namely, Indonesia, Malaysia, Singapore and Thailand. We construct an empirical model to account for the role of the real exchange rate and other economic fundamentals such as macroeconomic stability, terms of trade, capital goods investment, external demand and human capital. The study makes use of a panel data and estimates an export equation using a fixed effect model. The findings in this study strongly corroborate results from the theoretical framework that exchange rate misalignment and exchange rate variability have significant impacts on export performance. The study also finds evidence that the export growth path or these selected economies are dependent on global demand conditions, especially demand from OECD countries.
\end{abstract}

Keywords: Real exchange rates, Exchange rate misalignment, Panel data, Fixed effect model

\section{Introduction}

This paper analyses the impact of real exchange rate (RER) competitiveness and other economic fundamentals such as investment in capital goods, term of trade, human capital, and external demand on export performance in the selected Southeast Asian economies of Indonesia, Malaysia, Singapore and Thailand. A panel data is formed by combining the time series data of these four countries.

This work extends the work of Elbadawi (1998) and several others like Sekkat and Varoudakis (2000). It unifies two theoretical models of Rodrik (1994) and Paredes(1989). Rodrik's model, motivated by the export experiences of Taiwan and Korea explains rapid export growth as being driven by a sustained boom in capital investment. Paredes' model, influenced by the Latin American experiences predicts a significant role for RER competitiveness and RER stability in the determination of export supply.

\section{Previous empirical research}

There are several empirical models to examine the impact of exchange rate policies on exports of goods and services. Balassa (1990) studies the responsiveness of exports of goods and services to RER-related price incentives. This study was conducted for a panel of 16 Sub-Saharan African (SSA) countries. Sapir and Sekkat (1995) showed that the impact of RER, RER volatility and misalignment vary across different sectoral levels and exchange rate regimes.

Sekkat and Varoudakis (2000) extended the work of the above-mentioned studies by incorporating two more exchange rate policy indicators, namely RER volatility and RER misalignment. The study was conducted for selected SSA countries. The study postulated the following relationship between export volume and exchange rate variables:

$$
\log \left(X_{i}\right)=\alpha_{0}+\alpha_{1} \log \left(M N F_{i}\right)+\alpha_{2} \log \left(E_{i}\right)+\alpha_{3} \log \left(V_{i}\right)+\alpha_{4} \log \left(m i s_{i}\right)+\varepsilon_{i},
$$

\section{Where,}

$X_{i}$ is the ratio of export of sector $i$ over $G D P, M N F$ is the ratio of total manufactured value added to $G D P, E$ is the effective exchange rate (RER), $V$ is the volatility of the RER, mis is a measure of misalignment and $\varepsilon$ is the error term. 
Paredes (1989) found no significant link between export supply and exchange rate uncertainty for Chile and Peru. Grobar (1993) conducted a study to assess the impact of exchange rate volatility on export for ten developing countries (Argentina, Brazil, Colombo, Greece, Malaysia, Mexico, Philippines, South Africa, Thailand and Yugoslavia). The study lent support to the hypothesis that exchange rate volatility negatively affects exports. The study however found that misalignment did not have a significant impact on exports for the ten countries.

Rodrik (1994) showed that the sustained export growth in Korea and Taiwan was not achieved due to currency depreciation. The upward trend in export and trade in these countries are attributed to the increased investment in capital goods, research \& development and human capital development. These investments have enhanced the productivity and competitiveness of the goods and services produced in these two Asian 'tiger economies'.

Elbadawi (1998) conducted a study on more than sixty countries analyzing the role of real exchange rate in the non-traditional exports of Africa, and comparing it with the more successful non-African countries. Elbadawi's specification for the export demand function incorporated features from both Rodrik's and Paredes' models. Elbadawi's formulation of the export demand function is as follows:

$$
\begin{aligned}
\log \left(\text { XNTY }_{t}\right)= & \beta_{0}+\beta_{1} \text { RERMIS }_{t}+\beta_{2} \text { RERVAR }_{t}+\beta_{3} \log \left(\text { MM }_{t}\right) \\
& +\beta_{4} \log \left(\text { TOT }_{t}\right)+\beta_{5} \text { TOTVAR } \beta_{6} S C H_{t}+\beta_{7} \text { OECYB }_{t} \\
& +\gamma_{1} D S S A_{t}+\gamma_{2} D E A_{t}+\gamma_{3} D L A C_{t}+\varepsilon_{t},
\end{aligned}
$$

Where, $X N T Y$ is the ratio of non-traditional exports to GDP (both in current dollars); RERMIS is the real exchange rate misalignment; RERVAR real exchange rate variability in logs; MM is imports of machinery over GDP; TOTVAR is variability in the terms of trade; $S C H$ is an index of schooling (the average of the primary and secondary enrolment ratios). $O E C Y B$ is OECD countries' GDP per worker (in constant dollars); and DSSA, DEA and DLAC are dummies for Sub-Saharan Africa, East Asia and Latin America (proxing for differing supply conditions), respectively.

Elbadawi's study indicated that RER misalignment, RER volatility, investments in machinery and schooling have significant impact on export performance. RER variability was found to have a negative impact on export performance.

The next section proposes a model similar to that presented in Elbadawi (1998) and Sekkat and Varoukadakis (1999) to assess the impact of exchange rate and human capital on the export path for the selected economies.

\section{The model data}

This study makes use of a panel data which is formed by pooling the time series, cross-section data of Indonesia, Malaysia, Singapore and Thailand. The use of panel data is believed to be appropriate here because of the limited number of observations for each country.

Panel data sets are typically wide but short i.e. with wide cross sectional units but short number of years as in the study of Elbadawi (1998). In this study however because the cross sectional units are only four- since we focus on only four countries, the panel data formed is not the typical wide and short panel. However, the advantage here is we reduce the large averaging effect that occurs in wide panel data sets. Thus, the estimation obtained in this study would better reflect the situation in these four countries.

There are three models that can be used for analysing panel data. The first model is to simply combine or pool all the time-series and cross section data and then estimate the underlying model using ordinary least squares (this is referred to as pooled least squares). The intercept is assumed to be common.

The second model involves the recognition that omitted variables may lead to changes in the cross section and time-series intercepts. This model is referred to as the fixed-effects model, which allow for intercepts to be different for the different cross-sections.

The third model allows for the variation in the cross-sections and also the periods. This method is called the random-effects. The method is essentially a variation of the generalized least squares estimation.

Consider the following model for the export function for the selected ASEAN economies:

$$
y_{i t}=\alpha_{i t}+\beta_{i}^{\prime} x_{i t}+\varepsilon_{i t},
$$

where, $i(i=1, \ldots n)$ is the cross-section units (countries) and $t(t=1, \ldots, \mathrm{T})$ is the periods. The dependent variable $y$ measures the export function. The vector $\beta$ is the parameter of interest. The residual is denoted as $\mathcal{E}$ residual. The design matrix $(\boldsymbol{x})$ for the model is

$$
\boldsymbol{x}=[\text { RER, RERMIS, RERVAR, } \log (\mathrm{MM}), \log (\mathrm{TOT}), \text { ILLITERATE, OECD }]
$$

$R E R$ is the real exchange rates defined such that an increase in RER represents an appreciation (data from IMF International Financial Statistics, 2000). RERMIS is real exchange rate misalignment, obtained from subtracting ERER from RER and expressed as a percentage of ERER. (for theoretical and empirical work on the equilibrium exchange rate 
ERER see Mohamad and Nair (2007). A positive figure represents an overvaluation. All RER, ERER, and RERVAR are expressed in logs, while RERMIS is expressed in percentages.

The equilibrium RER level (ERER) is also used to find out which of the ER variables most significantly affect exports. All RER, ERER, and RERVAR are expressed in logs, while RERMIS is expressed in percentages. This model extends Paredes' model by explicitly linking export supply to the actual level of RER, level of the equilibrium RER and to the degree of RER disequilibrium. These different measures of RER can also proxy ER policy and therefore the model can assess the impact of ER policies on export.

RERVAR is RER variability measured from the monthly standard deviation of the real effective exchange rates (data from IMF World Economic Outlook WEO 2000 database), This measure is used to proxy macroeconomic stability relevant for export performance.

MM is machinery imports as a percentage of GDP. TOT is terms of trade (data was obtained from IMF WEO 2000).

ILLITERATE is the illiteracy rate for adult (percentage of people 15 and above, data from World Bank, World Development Indicator WDI, 2000). This measure was used to replace schooling as the data is more complete. Illiteracy rate also proxies the initial stock of human capital in the different countries.

OECD is average GNP per capita of OECD countries in constant 1995 USD (the individual GNP per capita data for 23 OECD countries were obtained from World Bank WDI 2000) and is used to control for the level of world demand.

As mentioned earlier, there are three possible models that can be derived from the (3). They are the pooled, fixed and random models. The pooled model assumes the intercepts for the countries are identical, that is,

$$
\alpha_{i t}=\alpha
$$

The difficulty with pooled least squares is its assumption of constant intercept and slope are unreasonable.

The fixed effects for the model in (3) is estimated to allow for different intercepts for different cross-section units, thus:

$$
\alpha_{i t}=\alpha_{i} \text {, where } E\left(\alpha_{i} \varepsilon_{i t}\right) \neq 0
$$

The random effects model on the other hand treats intercepts as random variable across pool members so that:

$$
\alpha_{i t}=\alpha+u_{i}, \text { where } E\left(u_{i} \varepsilon_{i t}\right)=0
$$

For our problem we could not estimate random effects model as it requires the number of cross-sections to be greater than the number of regressors. In our case, the number of cross-sections (countries) is four, while the number of regressors in the model is seven.

In order to test which model is better between the pooled least squares regression model and the fixed effects model, we conduct the following F-test, where the null and the alternative hypothesis are as follows:

$H_{o}: \alpha_{i t}=\alpha$

$H_{A}: \alpha_{i t}=\alpha_{i}$

The $F$-test statistic is given as follows (Greene 2000: 562):

$$
F=\frac{\left(R_{f e}^{2}-R_{p}^{2}\right)}{\left(1-R_{f e}^{2}\right)} \frac{(n T-n-k)}{(n-1)}: F_{n-1, n T-n-k},
$$

The test statistics in (4) follows an $F$-distribution with $(n-1)$ and $(n T-n-k)$ degrees of freedom.

The model in (3) was estimated using a sample of pooled cross section and time series data. Two different measures of exports were used as dependent variables, and these were estimated separately. These are total exports of goods and services $(\log X)$, total export of manufactured goods $(\log X \operatorname{manf})$

The model in (3) was first estimated using pooled least squares technique with assumption of a common intercept and then using fixed effects model that allow for different intercepts representing each country. The coefficients of all the regressors are assumed common across the cross section units (the four countries). The use of country dummies to obtain the different intercepts can capture to some extent the initial differences that exist among these countries. The fixed-effect model was estimated using the generalised least square (GLS) method.

\section{Results and discussion}

Initial results of regressions show DW statistics having values close to zero, suggesting existence of autocorrelation. To correct for this an AR(1) term is introduced which significantly improves the model. We also estimated the models using the White Heterosckedasticity estimator (to correct for the existence of heterosckedasticity) and the generalized least squares method with cross sections weights. Regressions using RER were found not to be significant, and so the tables report regressions that exclude this variable. 
Tables 1 and 2 report the results for the 2 export functions. Each table contains three fixed effects regressions. Equation 1 incorporates the full set of variables, while regression 2 excludes imports of machines (MM) and regression 3 excludes RERMIS. Equation 2 and 3 are designed indirectly to test Rodrik's conclusion that capital goods are important determinants for export growth.

The estimated regressions for the export functions appear to fit the data very well with more than $95 \%$ of the variation in exports explained by the model.

Generally, the parameters in the models have the expected signs and most are significant at $1 \%$ level. For Table 1, in equation 1 RERMIS is not significant but RERMIS becomes significant in equation 2, when the variable imported machinery (log MM) is excluded. The negative significant impact of RERMIS means that an overvaluation of the RER relative to its equilibrium level will tend to decrease exports, while an undervaluation will increase it. The magnitude however is rather small.

Unlike the findings in Elbadawi (1998), the variable ERER in our study was found to be highly significant in all regressions. This implies that not only does exchange rate misalignment matter, the position of the equilibrium rate also is important, with higher ERER leading to reduce amount of exports.

RER variability was found to be damaging to exports as revealed by the significant and negative coefficient of RERVAR. The magnitude however is much less compared to the damaging effect of an appreciating ERER but bigger than the effect of RERMIS. The results for the coefficient of imports of machinery (MM) are highly significant with the expected positive signs in all the regressions. The findings lend further support to the hypothesis that this factor is an important catalyst enhancing the export growth in these East Asian countries.

The estimated coefficients for ILLITERATE confirm the importance of human capital is an important factor for the export from these countries. A reduction in the illiteracy rate boost total export of goods and services produced in these countries.

For the OECD variable, only equation 2 show weak significance (at $10 \%$ ). the result lends some support to the importance of external demand in these countries.

Finally all country constants (intercepts) have positive values and are highly significant. The fixed effects values reported in the tables indicate that the fixed effects model with different country intercepts are more efficient than the model which assumes constant intercept. From the empirical results, Malaysia seems to have the highest initial advantages in the production of total export of goods and services compared to the other three countries.

\section{Conclusion}

.This work has policy implications concerning the importance of various exchange rate measures that affect exports. The RER misalignment measure, RERMIS, is found to be negatively and significantly associated with export. This means that an undervaluation of RER can be used to promote export, while an overvaluation will tend to reduce export. However, the results also suggest that, variability may be a more important variable to consider than the level of misalignment. This finding can contribute towards a policy choice when policy makers are faced, for example, with the trade-off between stability of the exchange rates and the possibility of serious misalignment caused by pegging.

This study also gives strong support for the contribution of imported investment in capital towards export growth. The results for OECD countries average GNP per capita (OECD), terms of trade (TOT) and illiteracy rate ILLITERATE were mixed, but are generally consistent with predictions.

Empirical findings from this study not only corroborate the view that imports of investment in capital goods, basic capabilities, and perhaps some strategic interventions to resolve market failures are important for successful export-orientation; but also give evidence for the contributions of competitive and stable exchange rates.

\section{References}

Balassa, B. (1990). Incentive policies and export performance in Sub-Saharan Africa. World Development 18 (3), pp. 383-391.

Elbadawi, I. (1998). Real exchange rate policy and non-traditional exports in developing countries. Research for Action 46, UNU/WIDER.

Grobar, L.M. (1993). The effect of real exchange rate uncertainty on LDC manufactured exports. Journal of Development Economics, 41, pp. 367-376.

Mohamad, S. \& Nair, M., (2007). Were currencies deliberately undervalued to promote exports? An empirical examination of selected ASEAN Countries. The Journal of Applied Economics and Policy Analysis 1,1, pp. 184-193.

Paredes, C. (1989). Exchange rate regimes, the real exchange rate and export performance in Latin America. Brookings Discussion Papers in International Economics, No 77 August. The Brookings Institute, Washington, DC.

Rodrik, D. (1994). Getting interventions right: how South Korea and Taiwan grew rich. NBER Working Paper Series, No. 4964, December. 
Sapir, A., and Sekkat, Kh., (1995). Exchange rate regimes and trade prices: Does the EMS matter? Journal of International Economics, 30, pp. 75-95.

Sekkat, Kh., and Varoudakis, A. (2000). Exchange rate management and manufactured export in Sub-Saharan Africa. Journal of Development Economics 61, pp. 237-253.

Table 1. Estimation of Equation 5 Using Dependent Variable Total Export of Goods and Services (log X)

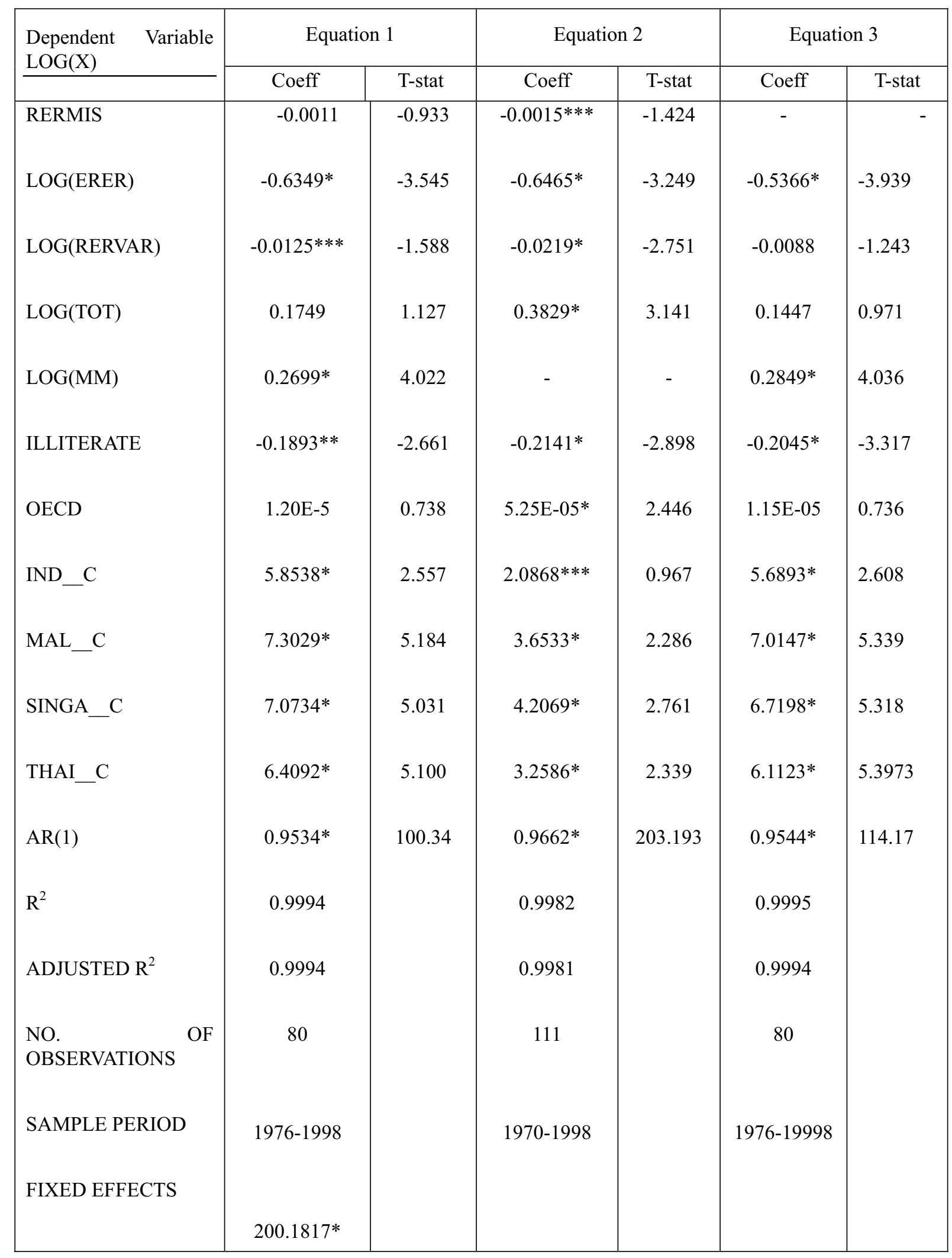


Table 2.Estimation of Equation 5 Using Dependent Variable Export of Manufactured Goods (log Xmanf)

\begin{tabular}{|c|c|c|c|c|c|c|}
\hline \multirow{2}{*}{$\begin{array}{l}\text { Dependent Variable } \\
\text { LOG(Xmanf) }\end{array}$} & \multicolumn{2}{|c|}{ Equation 1} & \multicolumn{2}{|c|}{ Equation 2} & \multicolumn{2}{|c|}{ Equation 3} \\
\hline & Coeff & T-stat & Coeff & T-stat & Coeff & T-stat \\
\hline RERMIS & $-0.0041 *$ & -2.453 & $-0.0050^{*}$ & -2.170 & - & - \\
\hline LOG(ERER) & $-1.2439 *$ & -4.672 & $-1.3955^{*}$ & -4.338 & $-0.9774 *$ & -3.654 \\
\hline LOG(RERVAR) & $-0.0222 *$ & -2.396 & $-0.0406^{*}$ & -2.643 & -0.0098 & -1.138 \\
\hline LOG(TOT) & $0.4632 * * *$ & -1.613 & 0.0199 & -0.072 & $-0.5477 * *$ & -2.089 \\
\hline LOG(MM) & $0.5922 *$ & 8.812 & - & - & $0.6126^{*}$ & 8.240 \\
\hline ILLITERATE & $-0.0376^{*}$ & -1.665 & $-0.0696^{*}$ & -2.167 & $-0.0592 *$ & -2.498 \\
\hline OECD & $2.9 \mathrm{E}-05^{* * *}$ & 2.954 & $6.6 \mathrm{E}-05^{* *}$ & 2.376 & $1.40 \mathrm{E}-05$ & 0.653 \\
\hline IND_C C & $11.7719^{*}$ & 8.625 & $8.4350 *$ & 5.306 & $11.8293^{*}$ & 8.435 \\
\hline $\mathrm{MAL} \_\mathrm{C}$ & $12.3073 *$ & 8.848 & $9.956^{*}$ & 6.507 & $12.238 *$ & 8.578 \\
\hline SINGA_C & $12.5010^{*}$ & 9.106 & $10.3020^{*}$ & 6.988 & $12.2399^{*}$ & 8.738 \\
\hline THAI_C & $11.6662 *$ & 8.445 & $8.3747^{*}$ & 5.813 & $11.4172 *$ & 8.229 \\
\hline $\operatorname{AR}(1)$ & $0.7 *$ & 5.673 & $0.7433 *$ & 6.718 & $0.6752 *$ & 7.310 \\
\hline $\mathrm{R}^{2}$ & 0.9995 & & 0.9977 & & 0.9994 & \\
\hline ADJUSTED R ${ }^{2}$ & 0.9994 & & 0.9973 & & 0.9993 & \\
\hline $\begin{array}{l}\text { NO. OF } \\
\text { OBSERVATIONS }\end{array}$ & 70 & & 70 & & 70 & \\
\hline SAMPLE PERIOD & 1980-1998 & & $1980-1998$ & & 1980-1998 & \\
\hline FIXED EFFECTS & $244.5770^{*}$ & & & & & \\
\hline
\end{tabular}

\section{Notes for all tables}

RERMIS: Real Exchange Rate Misalignment $=(($ RER-ERER $) /$ ERER $) * 100$

ERER: Equilibrium Real Exchange Rate

RERVAR: Real Exchange Rate Variability

TOT: Terms of Trade measured in index 
MM: Import of Machines

ILLITERATE: Illiteracy Rate (\%) of adults 15 years and above.

OECD: Average OECD countries GNP per capita (in constant 1995 USD)

IND_C, MAL_C, SINGA_C, THAI_C are cross section (country) constants

AR(1): Autoregressive variable of lag one.

FIXED EFFECTS give F statistics of the test of the non-existence of a fixed effects

$*, * *, * * *$ significant at $1 \%, 5 \%$, and $10 \%$ levels respectively 